\title{
Alveolar-cell carcinoma: a problem in sputum cytodiagnosis
}

\author{
AI SPRIGGS, MARGARET COLE, MS DUNNILL \\ From the Laboratory of Clinical Cytology, Churchill Hospital, Oxford, and the Department of Histopathology, John \\ Radcliffe Hospital, Oxford
}

SUMMARY Cytology and histology are correlated in a series of 22 cases chosen to illustrate the differential diagnosis between clusters of benign bronchial or bronchiolar cells seen in sputum, and those of alveolar cell carcinoma or adenocarcinoma with alveolar spread.

Alveolar-cell carcinoma is characterised by clusters of small epithelial cells in spherical or irregular formations, none showing enough polarity to distinguish a smooth or palisaded surface. The appearances are most distinctive if vacuolation is absent. The diagnosis cannot, however, be confidently made in all cases from morphological features of cells in sputum.

A well-known recurrent diagnostic problem in laboratories of clinical cytology is the morphological distinction between clusters of non-ciliated cells from epithelium of the respiratory passages in benign disorders, and those of well differentiated adenocarcinoma. Cytological distinctions between different adenocarcinomas, whether alveolar, bronchial, or metastatic from extrapulmonary sites, while perhaps of less clinical importance, form an area of particular difficulty.

The present study is an attempt to correlate cytology and histology in cases where the latter is available, including for comparison certain cases with abnormal cytological findings whose benign course leads us to assume that no carcinoma was present.

\section{Material}

Relevant cases were chosen from the files of the Laboratory of Clinical Cytology, Churchill Hospital, which go back 30 years. Histological material covering the same period was available in the Histopathology Department, John Radcliffe Hospital. Many of the cases examined were incomplete in that the patient died within a few years without any biopsy or necropsy; even some "firm" clinical diagnoses were rejected, so as to avoid contamination of the series with misdiagnoses. The series is therefore highly selected, the criteria being (a) relevance to the cytological problem and (b) reliable evidence particularly whether malignant or benign.

HISTOLOGICAL CRITERIA

The terms alveolar cell carcinoma and bronchioloalveolar cell carcinoma are synonymous in many classifications - for example, in that of the World Health

Accepted for publication 12 May 1982
Organisation (1967) ${ }^{1}$ and a well differentiated form is sometimes called "pulmonary adenomatosis." Precise histological identification of these tumours by light microscopy alone may prove difficult as the appearances are often very similar to those of a peripheral primary or secondary adenocarcinoma. Certain histological criteria 2 point to a diagnosis of alveolar cell carcinoma - namelyo (i) an absence of primary carcinoma elsewhere, (ii) the absence of an intrinsic tumour of bronchogenic origin (iii) a peripheral location involving alveolar ducts and sacs, (iv) the interstitial framework of the lung remaining unaffected, and (v) a dominant histology unlike other lung tumours. The tumour is formed of cuboidal cells which line the alveolar connective tissue framework (Fig. 1). They have a basally placed nucleus and eosinophilic cytoplasm which often exhibits minute irregular projections into the alveolar lumen giving an appearance reminiscent of "decapitation" type secretion as seen in apocrine glands (Fig. 2). Cytoplasmic vacuolation is unusual but occasionally there is a papillary pattern. Mitoses are infrequent.

Ultrastructural studies ${ }^{3-9}$ have shown that these tumour cells often have characteristics of type II granular pneumocytes. Intracytoplasmic structures resembling lamellated bodies found in type II cells are frequently to be seen whereas mucus-secreting vesicles, which might be expected in an adenocarcinoma, are absent. As type II pneumocytes are concerned with production of surfactant in might be thought that bronchiolo-alveolar lavage fluid from patients with alveolar cell carcinoma would contain large quantities of this material. This has not always proved to be the case. ${ }^{5}{ }^{10}$ Yet using the immunoperoxidase method Singh, Katyal and Torikata ${ }^{11}$ have demonstrated surfactant apoprotein in three of 14 tumours with this diagnosis. They pointed out that the term bronchioloalveolar carcinoma covered a heterogeneous group of 


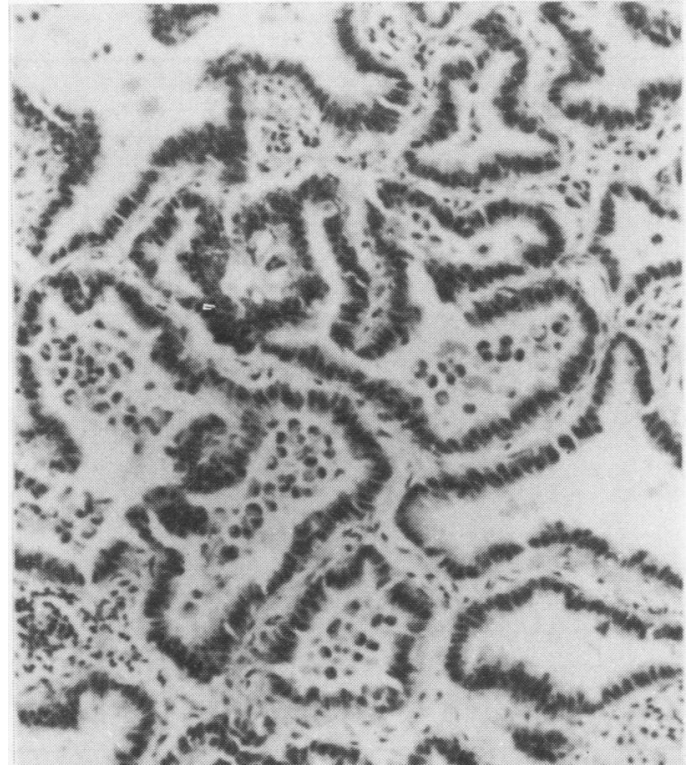

Fig. 1 Biopsy specimen from alveolar cell carcinoma (case $A F)$. The alveolar pattern is maintained but the entire alveotar wall is lined by uniform cuboidal cells instead of normal attenuated type I pneumocytes. (Haematoxylin and eosin $\times 100$ )

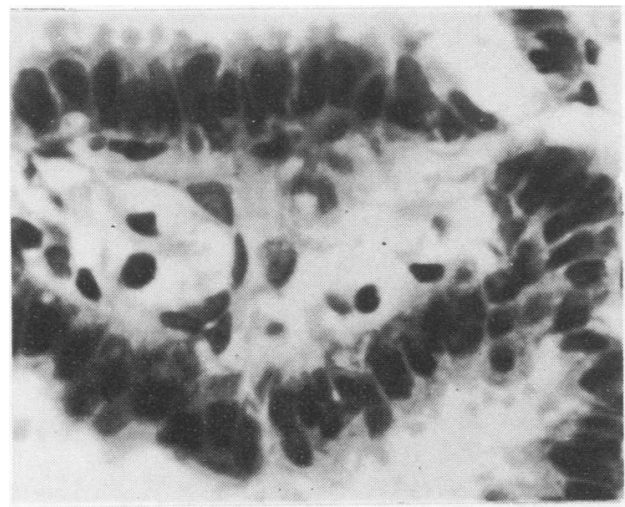

Fig. 2 Same specimen as Fig. 1. Many of the cells lining the alveolar connective tissue framework have minute irregular projections into the alveolar space reminiscent of "decapitation" secretion seen in apocrine glands. (Haematoxylin and eosin $\times 400$ ).

tumours and that many cases with this diagnosis were probably peripheral adenocarcinomas arising from metaplastic bronchiolar mucus-secreting cells.

Secondary adenocarcinoma from a primary tumour in the alimentary canal can cause diagnostic confusion but the mode of growth along alveolar walls in these tumours is different, tumour cells frequently being adjacent to normal alveolar lining cells (Fig. 3). In addition there is often clear evidence of mucus secretion.

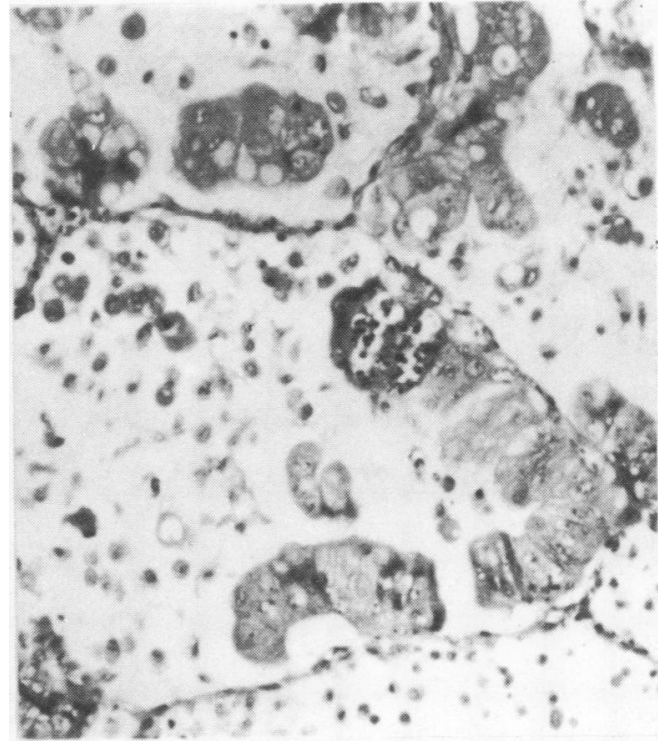

Fig. 3 Case SS. Secondary adenocarcinoma in the lung probably from a primary tumour in the stomach. The malignant cells are growing along alveolar walls which in some areas are still lined by normal flattened pneumocytes. (Haematoxylin and $\operatorname{eosin} \times 250$ ).

\section{Cases and methods}

The Table gives a breakdown of cases included in the series. The "benign" group are simply the most striking examples, where a diagnosis of adenocarcinoma has been seriously considered or even reported in error. The two other groups include all the cases available, where a cytological diagnosis of alveolar carcinoma had been made or suggested and could be histologically confirmed as belonging to one of these groups.

Sputum preparations were fixed in industrial ethanol and stained by the Papanicolaou routine. Although bronchial aspirates and brushings were available in some cases, the problems relating to these are rather different and they were not used in this study.

Histological material was reviewed by MSD and the entries under "Diagnosis" represent his opinion.

\section{Cytological results}

\section{(A) BENIGN}

The most striking development of benign bronchial cell clusters was seen in cases of bronchial asthma. The clinical presentation, occurrence of numerous eosinophils in the sputum, and presence of cilia on at least a few of the cell clusters usually prevent errors. Purely cytological features of the non-ciliated cell groups are as follows (Figs. 4-6). 
Table of cases

\begin{tabular}{|c|c|c|c|}
\hline & Age (yr) & Diagnosis & Evidence \\
\hline \multicolumn{4}{|l|}{ (a)Benign } \\
\hline DD & 70 & Bronchial asthma & Observed 4 yr \\
\hline EG & 56 & Bronchial asthma & Observed 4 yr \\
\hline $\mathrm{AP}$ & 72 & Bronchial asthma & Observed 2 yr \\
\hline MR & 35 & Pulmonary eosinophilia & Observed 18 yr \\
\hline MW & 78 & Obstructive airways disease & Observed 2 yr \\
\hline GW & 47 & Pneumonia & Observed $5 \mathrm{yr}$ \\
\hline A MacD & 54 & Chronic bronchitis & Necropsy 2 yrlater \\
\hline \multicolumn{4}{|c|}{ (b) Alveolar-cell carcinoma } \\
\hline PK & 69 & $\mathrm{AC}+$ fibrosing alveolitis & Drill biopsy \\
\hline $\mathrm{MC}$ & 61 & $\mathrm{AC}$ & Necropsy \\
\hline $\mathrm{ED}$ & 71 & $\mathrm{AC}+$ fibrosing alveolitis & Necropsy \\
\hline $\mathrm{AF}$ & 45 & $\mathrm{AC}$ & Drill biopsy. necropsy \\
\hline $\mathrm{AG}$ & 80 & $\mathrm{AC}+$ area of fibrosis & Necropsy \\
\hline $\mathrm{HI}$ & 77 & $\mathrm{AC}+$ fibrosis and amyloid & Lobectomy \\
\hline \multicolumn{4}{|c|}{ (c)Adenocarcinoma with alveolar spread } \\
\hline $\mathrm{ME}$ & 69 & Mucin-secreting & Necropsy \\
\hline $\mathrm{HC}$ & 65 & Bronchial origin & Necropsy \\
\hline IS & 63 & Adenocarcinoma in scarred lung & Lobectomy \\
\hline JR & 48 & Bronchial origin & Pneumonectomy \\
\hline $\mathrm{JM}$ & 63 & ? Bronchial origin & Necropsy \\
\hline LM & 54 & Adenocarcinoma & Lung biopsy \\
\hline MS & 79 & Adenocarcinoma in "honeycomb lung" & Necropsy \\
\hline SS & 69 & Probably secondary & Lobectomy \\
\hline NS & 68 & Probably secondary & Necropsy \\
\hline
\end{tabular}

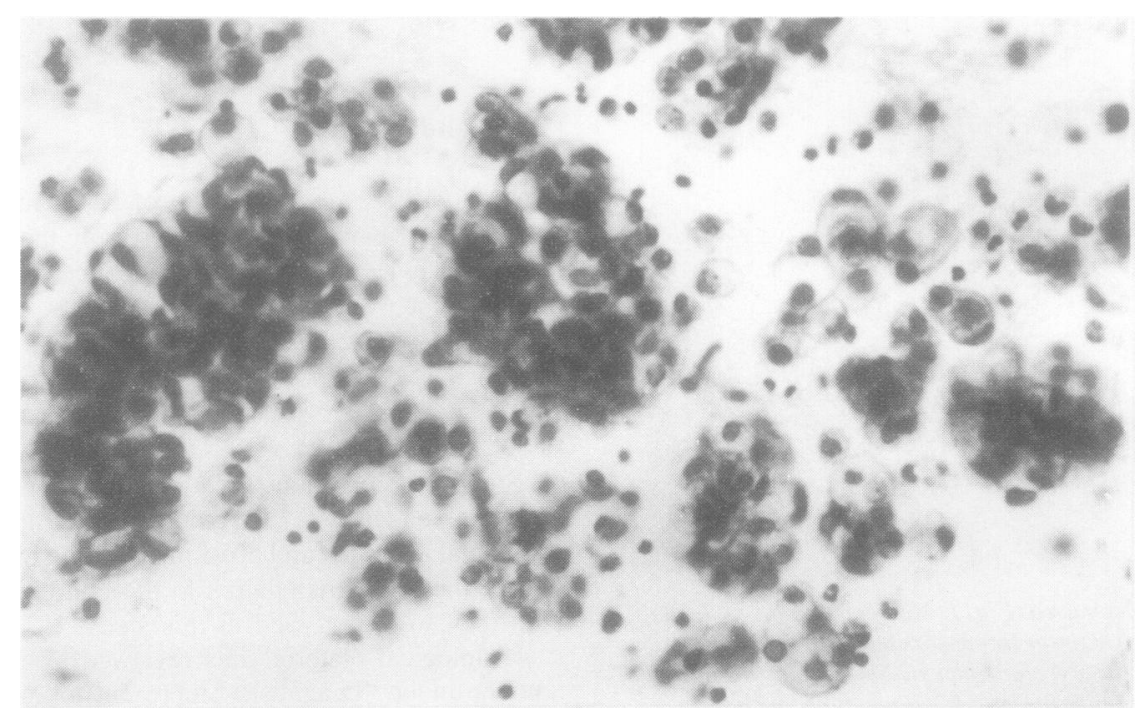

Fig. 4 Sputum of case EG (bronchial asthma). This field contains numerous rounded clusters of bronchial epithelial cells, none of them ciliated (Papanicolaou $\times 315$ ).

Rounded bronchial cells are found singly, in pairs or groups up to any size, with more or less vacuolation producing "signet-ring" forms and, in large clusters, the appearance of goblet cells. The clusters are irregular rather than spherical; their outlines may be "knobby" but there may also be a smooth convex border on at least one side corresponding to an epithelial surface.

Kidney-shaped or embryo-shaped clusters with a distinct "dorsal" surface (where cilia, if present, would be found), or even distinct palisading, are particularly useful indications that the condition is benign.

Inter-cell articulations and cells partially enveloped by 


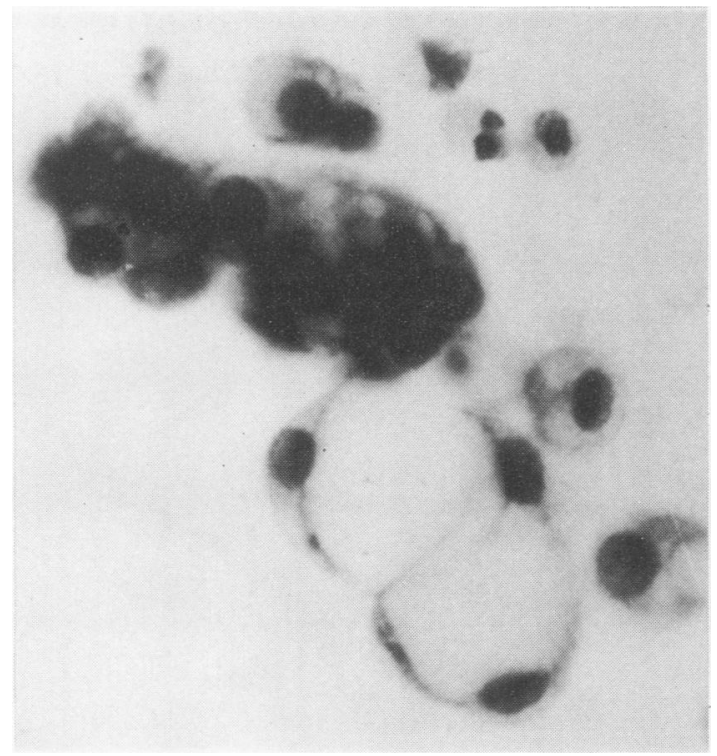

Fig. 5 Same specimen as Fig. 4, showing cell groups at higher magnification. (Papanicolaou $\times 800$ ).

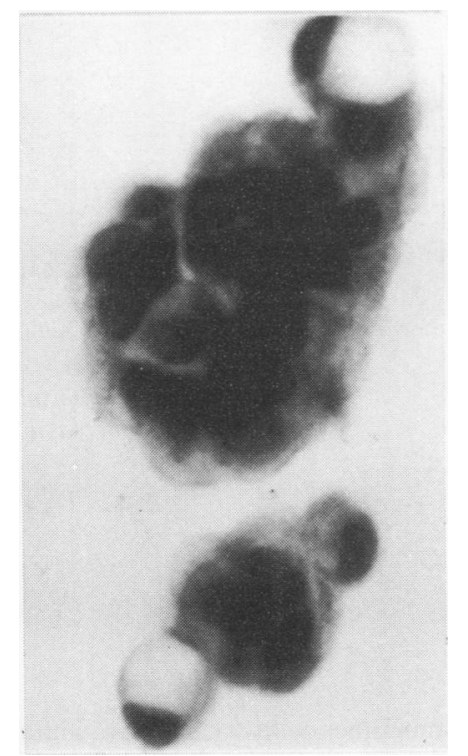

Fig. 6 Sputum of case DD (bronchial asthma). Note the suggestion of palisading on the convexity of the larger groups of cells. $($ Papanicolaou $\times 800)$.

others produce arrangements which the practised eye can recognise as distinct from the irregularity and loss of polarity of malignant cells. The nuclei of these benign cells are regular in size (6-8 $\mu \mathrm{m}$ diameter, occasionally reaching $10 \mu \mathrm{m})$ and seldom show significant nucleolar enlargement. In one case (MW) several mitoses were seen within a vacuolated cluster.

One case (GW) showed a totally different appearance. The sputum contained abundant lymphocytes as well as pus cells, and macrophages were also numerous. Scattered among these were loose clusters of cells which differed from surrounding macrophages in having larger, irregular-shaped nuclei and prominent nucleoli (Fig. 7). The largest nuclei measured $14 \mu \mathrm{m}$ across, but most measured no more than $8 \mu \mathrm{m}$. The clinical diagnosis was "pneumonia," and the patient recovered; she was well five years later.

In one other case (A MacD), some but not all clusters had irregular or convoluted nuclei similar to the above, sometimes with prominent nucleoli, and these gave rise to a false "suspect" diagnosis (Fig. 8).

\section{(B) ALVEOLAR-CELL CARCINOMA}

Six cases were considered histologically acceptable examples of this condition. The cytological picture varied from case to case, as one expects with malignant tumours, but was never indistinguishable from the picture just described.

In four cases the nuclei were small, not exceeding 10 $\mu \mathrm{m}$ in diameter. One of these (PK) showed clusters of very small cells, with nuclei measuring about $6 \mu \mathrm{m}$ across, with a single distinct nucleolus. Usually they had rather little cytoplasm, though there were occasional signet-ring forms. There were solid-looking clusters of cells with "knobby" outlines like blackberries, and without any "palisade" edge (Fig. 9). They were associated with many macrophages. In Case AG the cells were similar but more normal in size (up to $10 \mu \mathrm{m}$ diameter) and with several nucleoli. In Case AF most cells were of signet-ring form, and often occurred in groups of 2-5 cells rather than larger clusters.

Case MC showed loose clusters of cells with nuclei measuring 6-10 $\mu \mathrm{m}$ across, generally very uniform, with one or two prominent nucleoli which were usually quite small (Fig. 10), but sometimes clearly enlarged (Fig. 11). None of the clusters had a distinct outer edge. These cells were greatly outnumbered by macrophages.

In two cases (HI and ED) the nuclei were of larger size, ranging up to 14 or $16 \mu \mathrm{m}$ (Fig. 12). One of them (HI) also showed enlarged nucleoli. There was little or no vacuolation. Other features of these two were similar to those of the other four.

In none of these cases were the nuclei very irregular in shape, convoluted or folded. Usually they were either regular or had small indentations and irregularities of outline.

In no case were the cells arranged in the embryo-shaped structures, as described for some benign cell clusters. Instead, groupings were rosette-like or without polarity, or occasionally tending to form small three-dimensional spheres. 


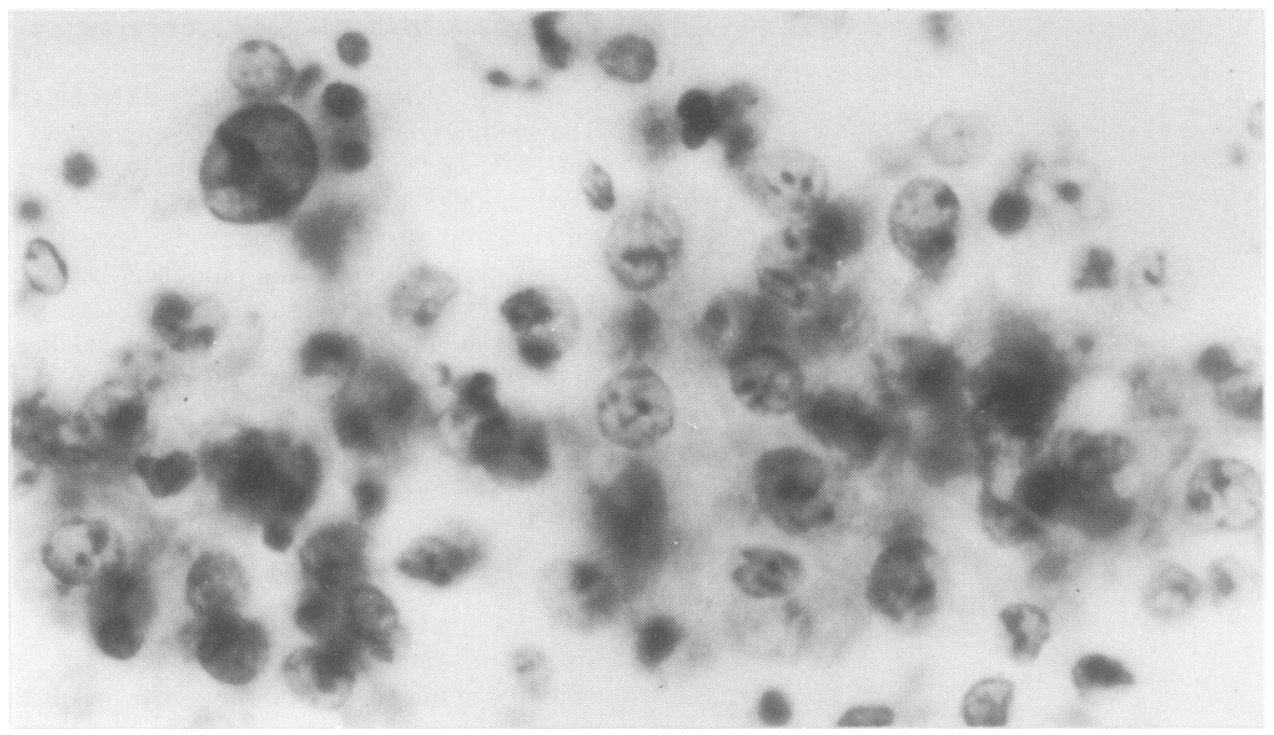

Fig. 7 Sputum of case GW (pneumonia). A false suspicious report was given on account of the pleomorphic nuclei with prominent nucleoli. (Papanicolaou $\times 800)$.

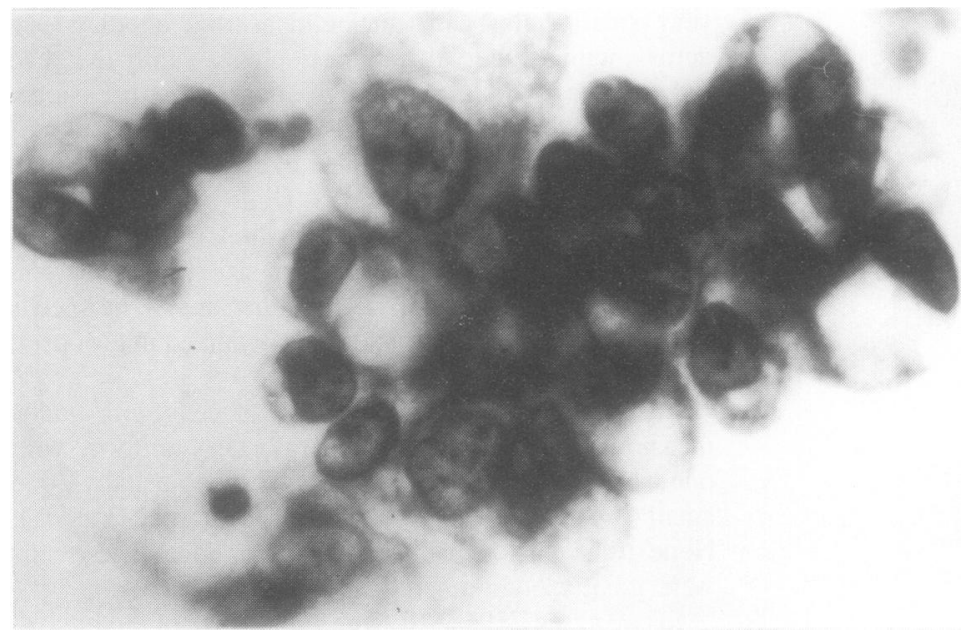

Fig. 8 Sputum of case AMacD (chronic bronchitis). A false suspicious report was given, because of the pleomorphic and sometimes very large cells composing these clusters, perhaps explained by polyploidy. (Papanicolaou $\times 800$ ).

\section{(C) ADENOCARCINOMA, BRONCHIAL OR}

\section{METASTATIC}

Because of the process of selection by which cases entered the series, these were all originally suspected on cytological or histological grounds to be classifiable as alveolar-cell carcinoma. No constant cytological difference was found, by which this group of cases could be distinguished from the previous one.

In one case (HC) the cells were small and comparable with those of AG. The cytoplasm was swollen but not vacuolated in the usual sense; occasional groups were roughly spherical. Case IS also had small cells in rounded clusters, sometimes with vacuolation within the clump. Cases JM and LM had cell clusters with rather pleomorphic nuclei and prominent nucleoli; in LM some of these nuclei were large, up to $15 \mu \mathrm{m}$ in diameter (Fig. 13). In both these sputa there were numerous eosinophils. In case NS most cells were vacuolated and nucleoli were very prominent. Two cases (JR and MS) had cell clusters of a more classical appearance for adenocarcinoma, with large nuclei and nucleoli, and in JR with massive vacuolation.

Finally, there were two cases in which the distinction from benign cell clusters, as seen in bronchial asthma, 


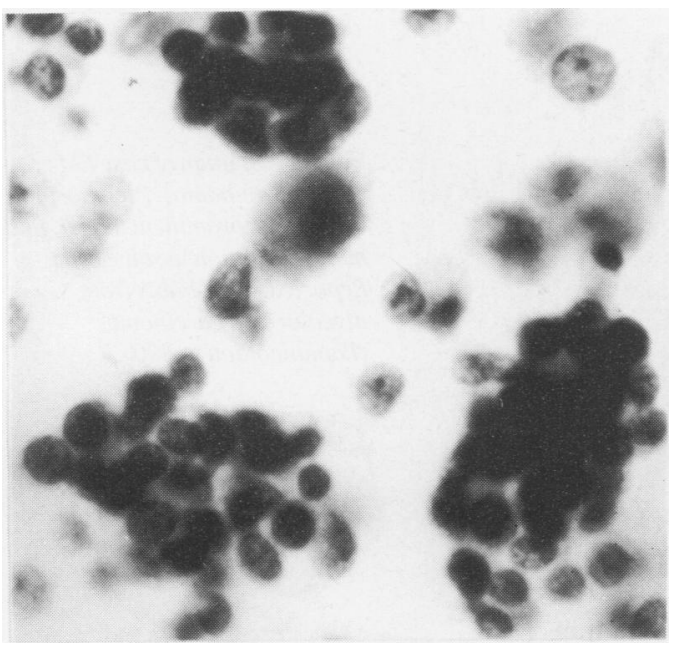

Fig. 9 Sputum of case PK (alveolar-cell carcinoma).

Blackberry-like clusters of very small epithelial cells without vacuolation. (Papanicolaou $\times 800)$.

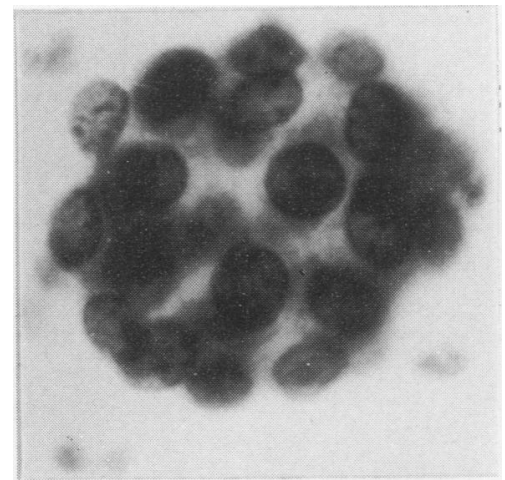

Fig. 10 Sputum of case MC (alveolar-cell carcinoma).A rounded cell cluster with "knobby" outline, similar to those shown in Fig. 9, but with larger cells. (Papanicolaou $\times 800)$.

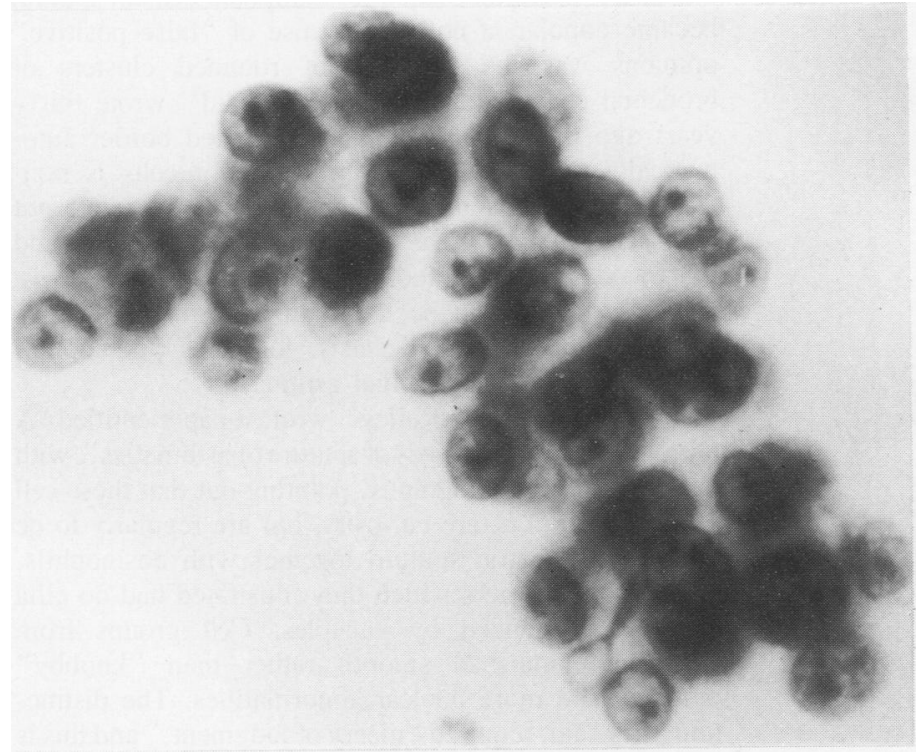

Fig. 11 Another cluster of cells from case MC (alveolar-cell carcinoma). There is no polarity, and in this group most nuclei show prominent nucleoli. (Papanicolaou $\times 800)$.

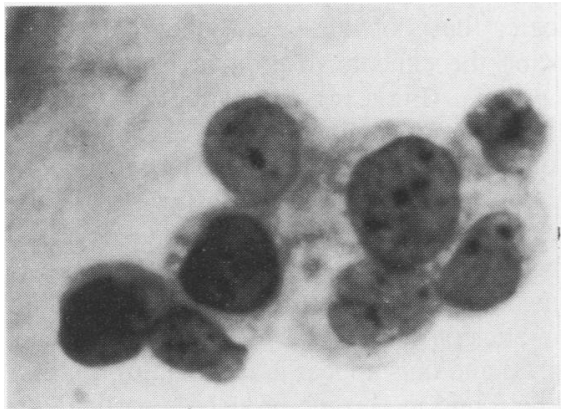

Fig. 12 Sputum of case ED (alveolar-cell carcinoma).

Relatively large nuclei and reduced cytoplasm.

(Papanicolaou $\times 800$ ) 


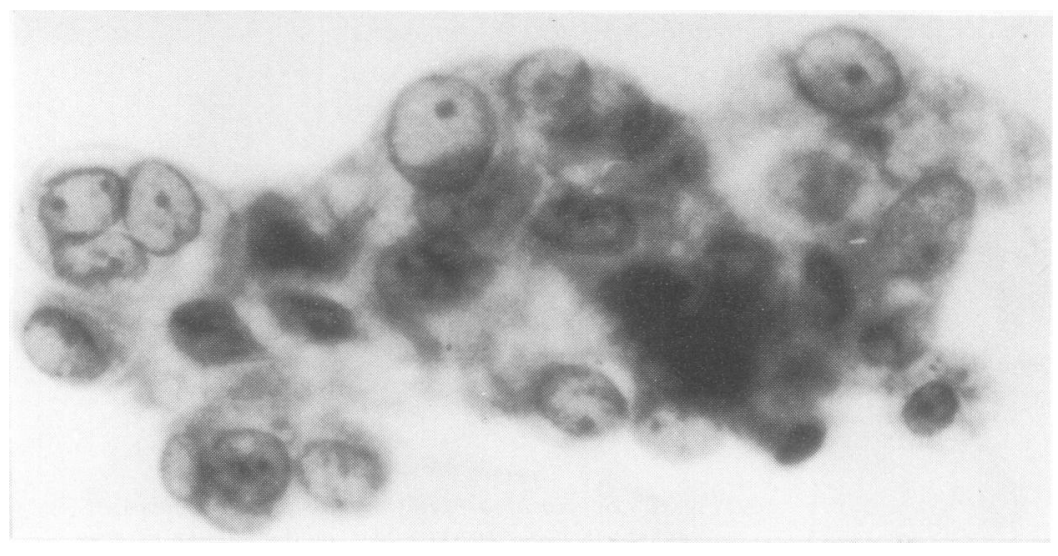

Fig. 13 Sputum of case LM (adenocarcinoma). Pleomorphic nuclei with prominent nuclei, and multinucleation in some cells. Reported as probably from alveolar-cell carcinoma. (Papanicolaou $\times 800$ ).

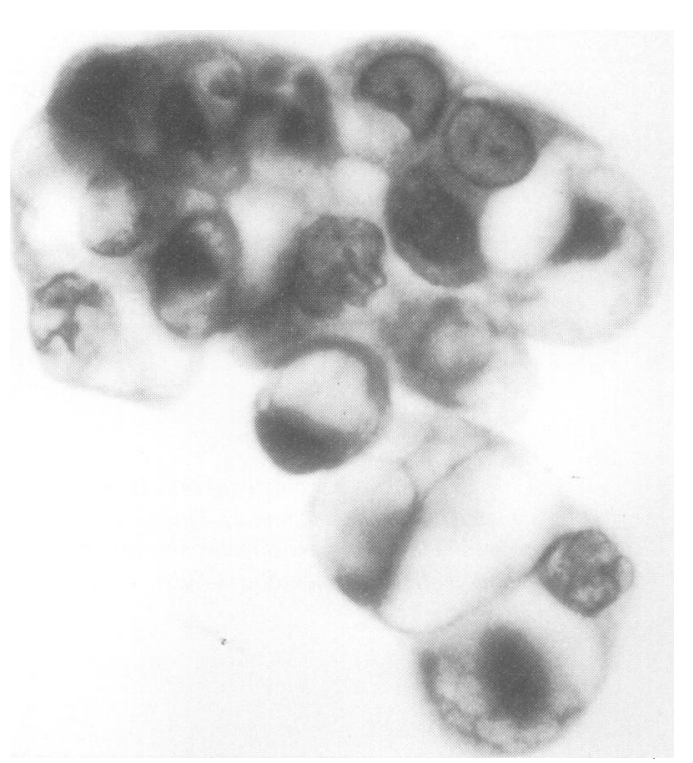

Fig. 14 Sputum from case SS (adenocarcinoma). Cell arrangement resembles that of benign bronchial cell clusters (cf Fig. 6), but the nuclei are larger and more irregular. (Papanicolaou $\times 800$ ).

could not be made on the grounds of loss of polarity. ME showed cell clusters with a distinct "surface" on one side, as well as ones without any polarity; the distinction could only be made on nuclear pleomorphism, with diameters sometimes reaching $20 \mu \mathrm{m}$ and coarse chromatin pattern. In case SS again some of the clusters had a distinct distal surface, and very few nuclei were unusually large; however, whole clusters consisted of cells with nuclei about $10 \mu \mathrm{m}$ across, which would be large for cases of bronchial asthma, and some of them had large nucleoli (Fig. 14). Eosinophils were numerous in this case also.

\section{Discussion}

"Large masses of cylindrical epithelium" were noted in the sputum of asthmatics almost a hundred years ago by Berkart. ${ }^{12}$ When the search for malignant cells in sputum became popular, a notorious cause of "false positive" opinions was the presence of rounded clusters of bronchial cells. Woolner and McDonald ${ }^{13}$ wrote thirty years ago that "the finding of a ciliated border automatically means that a given clump of cells is noncancerous." Unfortunately, clumps without cilia are not necessarily malignant, as was remarked by Philps ${ }^{14} 15$ and illustrated in Papanicolaou's Atlas of exfoliative cytology. ${ }^{16}$ They can be found in cases of pulmonary infarct, fibrosis, bronchiectasis, following pneumonia, and particularly in bronchial asthma.

In 1964 Naylor and Railey ${ }^{17}$ wrote a paper entitled "A pitfall in the cytodiagnosis of sputum of asthmatics", with many excellent photographs, pointing out that these cell clusters are not a rare curiosity, but are regularly to be found in asthmatic sputum together with eosinophils. Some of the clusters which they illustrated had no cilia and were distended by vacuoles. Cell groups from adenocarcinoma had smooth rather than "knobby" outlines, and more nuclear abnormalities. The distinction, they said, required "nicety of judgment," and this is still true today.

The histological basis of this finding may be seen in sections showing the exudate in bronchi from patients dying with asthma (Fig. 15). Shedding of delicate pseudostratified columnar epithelium is brought about by transudation of allergic oedema fluid from the submucosa across the mucous membrane. ${ }^{18}$ Only a few basal cells remain and from these mucosal regeneration takes place. The new epithelium is at first of a simple stratified variety, often exhibiting mitoses, with an absence of cilia. Should a further asthmatic episode occur these regenerating cells may also be shed and thus appear in the sputum. Similar changes may be found in chronic bronchitis particularly 


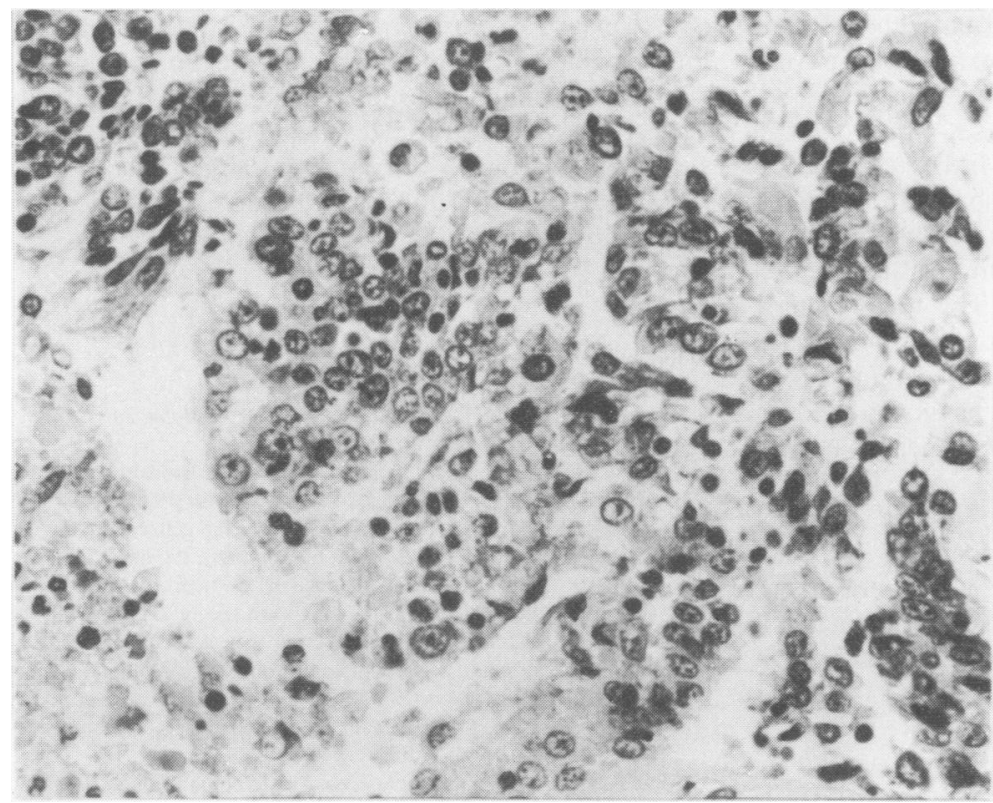

Fig. 15 Section of the exudate found in a bronchial lumen in a patient dying in status asthmaticus. The epithelial cells present show a variety of appearances and only an occasional typical columnar cell can be seen. (Haematoxylin and eosin $\times 400$ ).

during and after exacerbations due to secondary infection.

With experience over many years, certain features have emerged which are helpful in identifying the cells of bronchiolo-alveolar cell carcinoma in sputum and these can be found described and illustrated in the literature. ${ }^{19-25}$ These features are:

(a) Occurrence in firm clusters which may be spheroidal or finger-shaped, and are without cilia. They do not flatten on the slide but remain three-dimensional.

(b) Scarcity of separate free tumour cells.

(c) Small size of tumour cells (but Steinmann and Greul ${ }^{25}$ specify "larger than alveolar macrophages").

(d) Folding of nuclear membrane.

(e) Lack of nucleolar enlargement.

Whereas Roger et $a l^{20}$ and Johnston and Frable ${ }^{24}$ emphasise lack of pleomorphism Steinmann and Greul ${ }^{25}$ give pleomorphism as an important characteristic. The last authors also place weight on nuclear hyperchromasia (though with a narrow range of nucleocytoplasmic ratios), and evidence of phagocytosis.

Some of the above characteristics help to distinguish alveolar-cell carcinoma from bronchial-cell hyperplasia, while others distinguish it from ordinary bronchial or metastatic adenocarcinoma. These are two different problems, and it will be helpful to extend or modify the above criteria, in the light or our own series, as follows:

(i) BENIGN BRONCHIAL-CELLHYPERPLASIA VERSUS ADENOCARCINOMA (INCLUDING ALVEOLAR-CELL TYPE)

The usual picture seen in bronchial asthma is readily distinguishable because of the presence of cilia on at least some of the cell clusters. When these are absent it is still usually possible to recognise an epithelial surface, represented by the convex aspect of the structures. This was not seen in any of the cases accepted as alveolar-cell carcinoma, though it was found in two of the other adenocarcinomas (ME and SS); however in the first of those the nuclei were clearly large and pleomorphic, and only in the second would there be a difficulty in distinguishing from benign clusters.

In benign cell clusters there is very little variation in nuclear size from case to case, or from cell to cell within a cluster, whereas each neoplasm appears to have its own modal nuclear diameter. Nevertheless, benign cell clusters may contain single much larger cells, presumably polyploids, in which not only the nucleus is unusually large but also the nucleolus and the cytoplasm (Fig. 8).

The main departure from the above criteria concerns benign cell groups which appear to be dying or degenerate. Here, the nuclei may be unusually small, or else are very much folded and convoluted. Swelling of nuclei, enlarged nucleoli and a considerable degree of pleomorphism may be seen, but the nuclei concerned are pale rather than hyperchromatic. Case GW is the best example of this in our series.

Hyperchromasia has been mentioned by Steinmann and $\mathrm{Greul}^{25}$ as a characteristic of alveolar cell carcinoma. We have not found this useful in diagnosis, nor have other authors.

Vacuoles are of very little differential diagnostic importance because they are variably developed in both benign and malignant cell clusters. In the well differenti- 
ated clusters of bronchial asthma there may either be none at all, or scattered goblet-like vacuoles, or almost every cell may be vacuolated producing a structure like a chambered Nautilus. In one of our cases of alveolar-cell carcinoma $(\mathrm{AF})$ there were numerous little groups of two or more signet-ring cells, indistinguishable from similar groups which can be seen in benign conditions.

Phagocytosis is given as a feature of alveolar-cell carcinoma by Steinmann and Greul. ${ }^{25}$ This was strikingly seen in case NS, in our "adenocarcinoma" group, and is of course a well known feature of adenocarcinomas in general; it is very unusual to see many phagocytic cells in benign bronchial cell clusters, although there may be a few included polymorphs.

The three-dimensional appearance of cell clusters, sometimes described as "depth of focus," ${ }^{24}$ was not found to be a useful criterion. It was seen in the blackberry-like clusters of certain cases of alveolar-cell carcinoma, but even more strikingly in some of the benign cases, particularly in bronchial asthma.

\section{(ii) ALVEOLAR-CELLCARCINOMA VERSUS OTHER ADENOCARCINOMAS}

Since this distinction may be difficult histologically, even when necropsy permits a complete examination, it is not surprising that a clear division cannot yet be made on cytological grounds. In our own series, two cases classified as adenocarcinoma had much larger exfoliated cells than the others, as well as more obvious pleomorphism (cases MS and JR). Two others, mentioned already (ME and SS) were well enough differentiated to produce structures with "dorsal" surfaces. The remaining five cases were not cytologically distinguishable from those classified as alveolar-cell carcinoma. Distinguishing features of alveolar-cell carcinoma according to Gupta ${ }^{21}$ are lack of pleomorphism, small size, folded nuclei and abundant mucin-producing cytoplasm.

From what we have said, it would seem advisable for cytopathologists to avoid making this distinction, and to report sputum samples as showing the picture of "well-differentiated adenocarcinoma with alveolar-cell pattern" rather than to prejudge a disputed histological issue.

\section{Conclusion}

In any review of difficult cases, where one is searching for criteria rather than following them, there is a danger of serious confusion caused by a few misdiagnoses. On the one hand patients with tumours may survive unusually long, or necropsy may reveal no tumour when in fact a small one is present (and the pathologist may be unaware of a previous positive sputum report). On the other hand, a patient proved to have cancer of the lung may produce unusual cells in the sputum which do not, in fact, come from the growth. Consequently, recurrent features com- mon to many cases are more reliable than a few extreme or limiting findings used for drawing dividing lines.

From the pooling of results, a useful picture has already emerged and some mistakes made in the past can be avoided. Nevertheless there remains a grey area where it is better for the cytopathologist to equivocate, rather than to write down something which is not true.

\section{References}

1 World Health Organisation. Kreyberg L. ed. Histological typing of lung tumours. Geneva: WHO. 1967.

2 Delarue NC. Anderson W. Sanders D. Starr J. Bronchiolo-alveolar carcinoma: a reappraisal after 24 years. Cancer 1972;29:90-7.

3 Adamson JS. Senior RM. Merrill T. Alveolar cell carcinoma: an electron microscope study. Am Rev Respir Dis 1969:100:550-7.

${ }^{4}$ Coalson JJ. Mohr JA. Pirtle JK. Dee AL. Rhoades ER. Electron microscopy of neoplasms in the lung with special emphasis on the alveolar cell carcinoma. Am Rev Respir Dis 1970:101:181-97.

5 Kuhn C. Fine structure of bronchiolo-alveolar cell carcinoma. Cancer 1972:30: 1107-18.

" Nash G, Langlinais PC. Greenwald KA. Alveolar cell carcinoma: does it exist? Cancer 1972:29:322-6.

${ }^{7}$ Marcq M. Galy P. Bronchioloalveolar carcinoma: clinicopathologic relationships, natural history and prognosis in 29 cases. Am Rev Respir Dis 1973:107:621-9.

${ }^{8}$ Greenberg SD, Smith MN, Spjut HJ. Bronchioloalveolar carcinomacell of origin. Am J Clin Pathol 1975;63:153-67.

${ }^{9}$ Bedrossian CWM, Weilbaecher DG, Bentinck DC, Greenberg SD. Ultrastructure of human bronchioloalveolar cell carcinoma. Cancer 1975;36: 1399-413.

${ }^{10}$ Ramirez RJ. Schwartz B, Powell AR, Lee SD. Biochemical composition of human pulmonary washings. Arch Intern Med 1971;127:395-400.

$"$ Singh G, Katyal SL, Torikata C. Carcinoma of Type II pneumocytes: immunodiagnosis of a subtype of 'bronchiolo-alveolar carcinomas'. Am J Pathol 1981;102:195-208.

12 Berkart JB. On bronchial asthma: its pathology and treatment. 2nd ed London: Churchill. 1889:60.

1.3 Woolner LB, McDonald JR. Carcinoma cells in sputum and bronchial secretions: a study of 150 consecutive cases in which results were positive. Surg Gynecol Obstet 1949:88:273-90.

${ }^{14}$ Philps FR. Appearances which may cause confusion in the diagnosis of bronchial carcinoma from sputum examination. $\mathrm{Br} J$ Cancer 1954:8:422-6.

15 Philps FR. Vacuolated cells in the sputum simulating adenocarcinoma cells. Br J Cancer 1956:10:24-5.

${ }^{16}$ Papanicolaou GN. Atlas of exfoliative cytology: Cambridge. Mass: Commonwealth Fund, 1954.

17 Naylor B. Railey C. A pitfall in the cytodiagnosis of sputum of asthmatics. J Clin Pathol 1964:17:84-9.

${ }^{18}$ Dunnill MS. The pathology of asthma, with special reference to changes in the bronchial mucosa. J Clin Pathol 1960;13:27-33.

19 Kern WH. Cytology of hyperplastic and neoplastic lesions of terminal bronchioles and alveoli. Acta Cytol 1965;9:372-9.

${ }^{20}$ Roger V. Nasiell M, Linden M. Enstad I. Cytologic differential diagnosis of bronchiolo-alveolar carcinoma and bronchogenic adenocarcinoma. Acta Cytol 1976;20:303-7.

${ }^{21}$ Gupta RK. Value of sputum cytology in the differential diagnosis of alveolar cell carcinoma from bronchogenic adenocarcinoma. Acta Cytol 1981:25:255-8.

22 Tao LC, Delarue NC, Sanders D, Weisbrod G. Bronchiolo-alveolar carcinoma: a correlative clinical and cytologic study. Cancer 1978:42:2759-67.

${ }^{23}$ Koss LG. Diagnostic cytology and its histopathologic bases. 3rd ed. Philadelphia: Lippincott, 1979. 
24 Johnston WW, Frable WJ. Diagnostic respiratory cytopathology. USA: Masson, 1979.

${ }^{25}$ Steinmann G, Greul W. Factors in the cytological diagnosis of alveolar cell carcinoma. J Cancer Res Clin Oncol 1980;98:203-11.
Requests for reprints to: Dr AI Spriggs, Laboratory of Clinical Cytology, The Churchill Hospital, Headington, Oxford OX3 7LJ, England.

\section{The November 1982 issue}

\section{THE NOVEMBER 1982 ISSUE CONTAINS THE FOLLOWING PAPERS}

An antibiotic susceptibility testing trial organised as part of the United Kingdom national external microbiological quality assessment scheme JJS SNELL, DFJ BROWN, PS GARDNER

Sensitivity tests with cephalosporins PAMELA M WATERWORTH

Laboratory diagnosis of peritonitis in patients undergoing continuous ambulatory peritoneal dialysis PATRICIA FENTON

Bacteriuria in patients undergoing prostatectomy MELANIE WILLIAMS, DJ HOLE

A prospective study of cytomegalovirus and herpes simplex virus disease in renal transplant recipients DP WALKER, M LONGSON, NP MALLICK, RWG JOHNSON

Estimation of lymphocyte percentage and number on the Coulter Counter, Model S Plus Phase II JM ENGLAND, MC CHETTY, PM DE SILVA

Acute myelomonocytic leukaemia presenting as xanthomatous skin eruption JR O'DONNELL, P TANSEY, P CHUNG, AK BURNETT, J THOMSON, GA MCDONALD

Serum ferritin in normal individuals and in patients with malignant lymphoma and chronic renal failure measured with seven different commercial immunoassay techniques ANN GRAIL, BW HANCOCK, PAULINE M HARRISON

Alpha-1-antitrypsin phenotypes in malignant lymphoma F CALLEA, G MASSI, C DE WOLF-PEETERS, C LIEVENS, VJ DESMET

$T$ and $B$ lymphocyte markers in effusions of patients with non-Hodgkin's lymphoma AS KRAJEWSKI, AE DEWAR, EF RAMAGE

Enzyme histochemical analysis on cryosat sections of human bone marrow M CHILOSI, G PIZZOLO, G JANOSSY, MARGARITA BOFILL, L FIORE-DONATI

Immunological localisation of $\beta$-thromboglobulin and platelet factor 4 in human megakaryocytes and platelets KATHRYN M MCLAREN, DS PEPPER

A simple method for the separation and quantification of urinary porphyrins DT LEAHY, TG BRIEN
Antenatal diagnosis of steroid sulphatase deficiency: case report and literature survey RA SHERWOOD, BF ROCKS

Prospective comparison of the fluorescein dilaurate test with the secretin-cholecystokinin test for pancreatic exocrine function EJS BOYD, JGR CUMMING, A CUSCHIERI, RAB WOOD, KG WORMSLEY

Morphological study of the relation between accidental hypothermia and acute pancreatitis AK FOULIS

Liver function in septic shock JG BANKS, AK FOULIS, I MCA LEDINGHAM, RNM MaCSWEEN

Use of monoclonal antibodies for the histopathological diagnosis of human malignancy KC GATTER, $Z$ ABDULAZIZ, P BEVERLEY, JRF CORVALAN, C FORD, EB LANE, M MOTA, JRG NASH, K PULFORD, H STEIN, J TAYLOR-PAPADIMITRIOU, C WOODHOUSE, DY MASON

Measurement of striated muscle fibre diameters using interactive computer-aided microscopy G SLAVIN, C SOWTER, P WARD, K PATON

Jejunal crypt cell abnormalities associated with methotrexate treatment in children with acute lymphoblastic leukaemia CR PINKERTON, CHS CAMERON, JM SLOAN, JFT GLASGOW, NJT GWEVAVA

Demonstration of calcification fronts by in vivo and in vitro tetracycline labelling $J$ MCCLURE

Localisation of aluminium by histochemical and electron probe $x$-ray microanalytical techniques in bone tissue of cases of renal osteodystrophy PS SMITH, J MCCLURE

\section{Technical method}

Post-mortem inflation and fixation of human lungs - a modification of available apparatus DCS DURRANT

\section{Letters to the Editor}

\section{Book reviews}

Notices

\section{Some new titles}

Copies are still available and may be obtained from the PUBLISHING MANAGER.

BRITISH MEDICAL ASSOCIATION, TAVISTOCK SQUARE, LONDON WC1H 9JR. price $£ 5 \cdot 00$, including postage 